4. Bartalena L, Bogazzi F, Martino E. Adverse effects of thyroid drugs. Drug Safety 1996; 15: 53-63.

5. Richard AJ. Antithyroid arthritis syndrome-a case induced by carbimazole. J Rheumatol 1999; 26: 1851.

6. Cooper DDS. Antithyroid drugs for the treatmente of hyperthyroidism cause by Graves disease. Endocrinol Metab Clin North Am 1998; 27: 225 32.

7. Manero RFJ, Playan UJ, Acha PJ, Sanz PA. Methimazole arthritis in Graves Basedow disease. An Med Interna 1998; 15: 47-8.

8. Gittoes NJL, Franklyn JA. Hyperthyroidism. Current treatment guidelines. Drugs 1998; 55: 543-53.

\section{Enfermedad de Mondor. A propósito de un caso}

\section{Sr. Director:}

La enfermedad de Mondor es una entidad clínica rara y relativamente poco conocida. El cuadro clínico fue apuntado inicialmente por Fagge en 1869, posteriormente se recogieron casos esporádicos hasta que el cirujano francés Henri Mondor la describe en 1939, dándole su nombre. En 1976 se publica el primer caso en nuestro país ${ }^{1}$.

Esta enfermedad se caracteriza por una flebitis y periflebitis de una vena superficial del tórax, la vena torácica lateral o toracoepigástrica, que puede extenderse hacia la pared abdominal en la región epigástrica ${ }^{2}$, y en la mujer también a la piel de la mama ${ }^{3}$. Afecta principalmente a mujeres entre 21 y 55 años, aunque en un tercio de los casos puede aparecer en el varón.

La sintomatología se caracteriza por la aparición brusca de dolor en mama y/o pared anterior de tórax, seguida de la aparición de un cordón, estría o canal visible y palpable, doloroso en dicha zona.
Su etiología es desconocida pudiéndose relacionar en algunos casos con traumatismo local, esfuerzo muscular, procedimientos quirúrgicos en la mama y procesos febriles previos ${ }^{4}$. No parece existir relación con el cáncer de mama aunque se han descrito casos asociados al mismo ${ }^{5,6}$. También se han referido casos asociados a embarazo y puerperio ${ }^{7}$, a la arteritis de células gigantes ${ }^{8} \mathrm{y}$ a otras enfermedades sistémicas.

La imagen mamográfica puede ser característica con la vena trombosada presentando una morfología alargada o como las cuentas de un collar.

En la ecografía la vena se identifica como una estructura tubular hipoecoica con segmentos alternantes dilatados y engrosados.

Habitualmente evoluciona espontáneamente hacia la curación, si bien en ocasiones puede evolucionar a la cronicidad y complicarse con pequeñas necrosis cutáneas sobre la zona de la vena trombosada.

Presentamos el caso clínico de una mujer de 29 años que acude a consulta por presentar bruscamente un bulto, como un cordón discretamente doloroso en la zona anterior del tórax, inframamario y que aumenta con la hiperextensión del brazo del mismo lado.

Entre los antecedentes personales destacan ser fumadora habitual de diez cigarrillos al día. No refiere traumatismo previo ni otro proceso inflamatorio local, ni tampoco fiebre ni alteración del estado general. Los antecedentes familiares sin interés.

En la exploración se observaba en la cara anterolateral izquierda de tórax un cordón doble longitudinal con un surco o canal de unos $8 \mathrm{~cm}$ ligeramente doloroso a la palpación, cuyo trayecto terminaba en la zona central de la mama izquierda; dicho cordón se hacia más visible y palpable con la elevación de la mama (Figs. 1 y 2). No se apreciaba enrojecimiento ni aumento de temperatu-

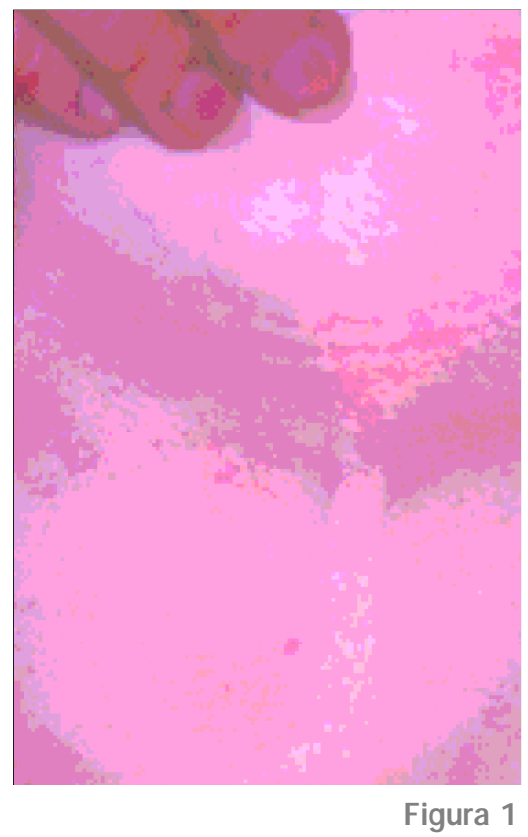

Imagen donde se aprecia el cordón longitudinal doble a nivel inframamario izquierdo

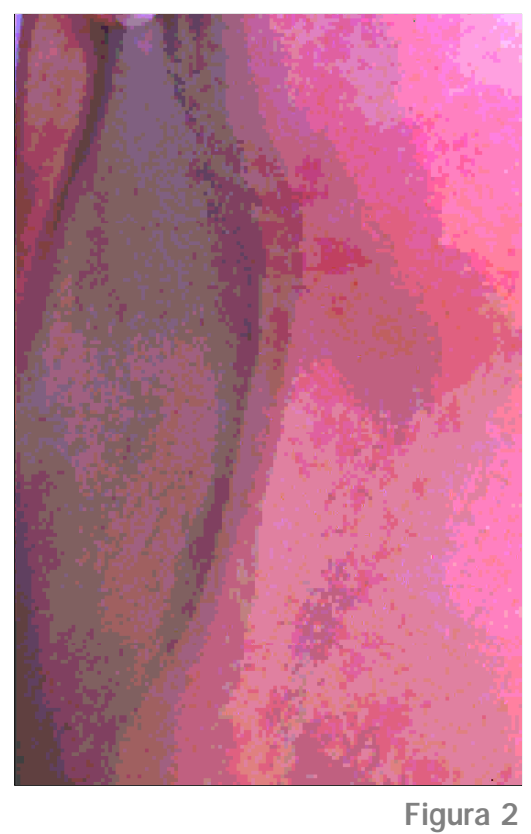

Con la elevación del brazo y la mama izquierdos se observa más nítidamente el cordón con un surco

central

ra a dicho nivel, tampoco se palpaba ninguna tumoración en las mamas ni tampoco adenopatías axilares ni supraclaviculares.

Se pautó tratamiento antiinflamatorio, se solicitó analítica 
completa con pruebas de coagulación y fibrinógeno, cuyo resultado fue normal. Aproximadamente en cuatro semanas la lesión disminuyó y la paciente quedó asintomática. Tras un año de evolución todavía se aprecian a la palpación dos pequeños cordones de aproximadamente $2 \mathrm{~cm}$ de longitud en la zona afectada.

Aunque en general la enfermedad de Mondor suele ser idiopática, no podemos olvidar que determinados casos van asociados a distintas patologías, por tanto dependiendo de las características del paciente, de la edad, antecedentes y exploración; la actitud variará con relación al seguimiento y petición de pruebas complementarias o derivación.

\section{E. A. González Romero, F. Fal- cón Morales*}

Especialista en Medicina Fami liar y Comunitaria. *Residente de tercer año Especialidad de Medicina Familiar y Comunita ria. Centro de Salud Rafael Al berti. Área 1 INSALUD. Madrid

\section{BIBLIOGRAFÍA}

1. Marrón Gasca J, Berdún Franco E, Giménez Serrano H, Ruíz de Azagra JV. Enfermedad de Mondor: Primer caso en España. Actas Dermosifiliogr 1976; 67: 571-82.

2. Mayo Aparicio WN, Muxi Moner C, Yuste Botey M. Enfermedad de Mondor. FMC 2000; 7: 646.

3. Arcelus Imaz I. Trombosis venosas En: Durán H, Arcelus I, García-Sancho L, González F, Álvarez J, Ferrández L, Méndez J. Cirugía venosa. Tratado de patología y clínica quirúrgicas. Madrid: Interamericana; 1983: p. 576

4. Pugh CM, De Witty RL. Mondor's disease. J Natl Med Assoc 1996; 88: 359-63.

5. Levi I, Baum M. Mondor's disease as a presenting symptom of breast cancer. Br J Surg 1987; 74: 700.

6. Chiedozi LC, Aghahowa JA. Mondor's disease associated with breast cancer. Surgery 1988; 103: 438-9

7. Duff P. Mondor's disease in pregnancy. Obstet Gynecol 1981; 58:117-9.
8. Diamantopoulos EJ, Yfanti G, Andreadis E. Giant-cell arteritis presenting as Mondor disease. Ann Internal Med 1999; 130: 78-9.

\section{Síndrome de Guillain-} Barré tras infección por virus de Epstein-Barr

\section{Sr. Director:}

El virus de Epstein-Barr (VEB) está relacionado con la mononucleosis infecciosa (MI), tumores como el linfoma de Burkitt de tipo africano y con el carcinoma nasofaríngeo. La enfermedad relacionada con mayor frecuencia es la $\mathrm{MI}^{1}$. Existen otros agentes que pueden originar un cuadro similar llamado síndrome mononucleósico principalmente el toxoplasma gondii, el citomegalovirus (CMV), los adenovirus, el virus de la inmunodeficiencia humana (VIH), el herpesvirus 6 y la rubeola entre otros.

La MI se caracteriza por la aparición de fiebre, hepatosplenomegalia, amigdalitis, adenopatías y molestias abdominales. El tratamiento es sintomático. Las complicaciones son numerosas, aunque infrecuentes. Probablemente las más habituales son de origen infeccioso como consecuencia del déficit inmune transitorio que caracteriza a la enfermedad. Menos del $1 \%$ de los pacientes desarrollan complicaciones neurológicas, fundamentalmente en forma de meningoencefalitis. Otros cuadros neurológicos asociados son el síndrome de Guillain-Barré (SGB) y el síndrome de Reye, la parálisis facial periférica, la neuritis óptica y la mielitis transversa.

El SGB se considera la principal patología neurológica postinfecciosa. Un estudio prospectivo realizado en el Hospital de Mas- sachusetts ${ }^{2}$ afirmaba que en un $27 \%$ de los casos no se han identificado enfermedad o antecedentes asociados con el SGB, en un $49 \%$ existía un antecedente de infección del tracto respiratorio, en un $10 \%$ existía una enfermedad diarreica y en un $3 \%$ una neumonía. En el 3\% de los casos se encontraron antecedentes de infección por VEB, el mismo tanto por ciento de infección por CMV. Más recientemente se ha implicado la infección por Campylobacter jejuni en pacientes con gastroenteritis aguda que desarrollaron posteriormente este síndrome. También puede aparecer durante la seroconversión en aquéllos con VIH. El otro 3\% de los casos constituyen una miscelánea en que se incluyen la enfermedad de Hodgkin, la cirugía, el lupus sistémico o la vacunación ${ }^{2}$.

\section{CASO CLÍNICO}

Se trata de una mujer de 20 años sin antecedentes patológicos de interés, ni alergias conocidas. No fuma ni bebe. No toma ningún tratamiento actualmente. Antecedente familiar de tío paterno con síndrome de Miller-Fisher hace veinte años. Trabaja como cajera en un supermercado.

Consulta porque siete días antes comienza con parestesias y pérdida de fuerza progresiva de ambos miembros inferiores, hasta impedir la deambulación. Unos quince días antes del comienzo de estos síntomas presentó astenia, febrícula y aumentadas de tamaño las adenopatías submandibulares. La exploración neurológica objetiva una paciente consciente y orientada, con lenguaje y comprensión normales, pupilas isocóricas y normorreactivas, sin nistagmos, con movimientos oculares externos, tono, masa muscular y balance muscular de miembros superiores normales, se observa paresia 4/5 en la flexión de la cadera izquierda así como en la flexión de la rodilla izquier- 